\title{
sciendo
}

\section{Kripke Was Right Even \\ If He Was Wrong: \\ Sherlock Holmes and the Unicorns}

\author{
Harold Noonan \\ University of Nottingham \\ DOI: $10.2478 /$ disp-2021-0003 \\ BIBLID [0873-626X (2021) 60; pp.51-69]
}

\begin{abstract}
In the Addenda to Naming and Necessity (1980), Kripke famously argues that it is false that there could have been unicorns, or more properly, that "no counterfactual situation is properly describable as one in which there would have been unicorns." He adds that he holds similarly that 'one cannot say of any possible person that he would have been Sherlock Holmes, had he existed." He notes the "cryptic brevity" of these remarks and refers to a forthcoming work for elaborations - the work being, of course, the John Locke Lectures (2013). Coming as it does at the end of Naming and Necessity, it is natural to read this discussion as drawing out consequences of Kripke's non-descriptivist picture of proper names and names of natural kinds. In fact, so much is suggested there by Kripke himself. The question thus arises: can the contentious claims quoted from the Addenda be defended independently of Kripke's rejection of descriptivism? I shall argue that, as appears from the John Locke Lectures, they can be.
\end{abstract}

\section{Keywords}

Kripke, fiction, names, unicorns, Sherlock Holmes.

In the Addenda to Naming and Necessity 1980, Kripke famously argues that it is false that there could have been unicorns, or more properly, that "no counterfactual situation is properly describable as one in which there would have been unicorns." He adds that he holds similarly that 'one cannot say of any possible person that he would have been Sherlock Holmes, had he existed'. He notes the "cryptic brevity" of these remarks and refers to a forthcoming work for elaborations- 
the work being, of course, the John Locke Lectures 2013. Coming as it does at the end of Naming and Necessity it is natural to read this discussion as drawing out consequences of Kripke's non-descriptivist picture of proper names and names of natural kinds. In fact, so much is suggested there by Kripke himself. The question thus arises: can the contentious claims quoted from the Addenda be defended independently of Kripke's rejection of descriptivism? I shall argue that, as appears from the John Locke Lectures, they can be. In fact, not only is this clear from the John Locke Lectures, but it is also clear from these that this is what Kripke himself thinks. Kripke's plausible claims in the Addenda provide no evidence against descriptivism. ${ }^{1}$

I begin by sketching out the line of argument from the rejection of descriptivism to Kripkes's theses about unicorns (or 'unicorns') and Sherlock Holmes (or 'Sherlock Holmes') it is natural to construct, having read only Naming and Necessity. Then I go on to explain, drawing first on the John Locke Lectures, how these theses can be defended without assuming the rejection of descriptivism. There are two lines of defence: one that proceeds on the assumption that the terms in question are fictional names of individuals and kinds, and a second which takes them to be mistakenly introduced, and so to be empty names of individuals and kinds (obviously, this second defence cannot support Kripke's specific claim about Sherlock Holmes, but another

\footnotetext{
${ }^{1}$ A referee wonders whether this line of defence of descriptivism is not, perhaps, "a bit futile", since "many philosophers of language regard Kripke's arguments against descriptivism as decisive", so "why bother to show the consistency of Kripke's two theses with descriptivism if descriptivism was proven to be false". Many philosophers do regard descriptivism as refuted by Kripke, but not all. Indeed, some of the most eminent philosophers of language writing in the post-Kripkean years do not. Michael Dummett (1973, 1981, 1991) and David Lewis (1984, 1997) consistently rejected Kripke's arguments. (As a reminder, Lewis (1997: 339) writes: "Did not Kripke refute the description theory .... I disagree... A version ... survives, causal descriptivism.") The equally eminent Jackson $(1998,2010)$ and Chalmers (2002) led the "descriptivist revival” — as described by Soames (2005) in the twenty-first century. Description theories are still among the views to which students are exposed in standard textbooks and handbooks (see for example 2021, four chapters of which, by Jackson, Noonan, Poller, and Wikforss and Häggqvist explicitly defend forms of descriptivism). So descriptivism is still a live option. However, unless the descriptivist can account for the data in Kripke's Appendixwhich are, I think, indeed data - descriptivism must be abandoned. That is why the task I have set myself in this paper is not futile.
} 
example about which Kripke would say the same, and, in fact, does say the same, is Vulcan, the hypothetical intra-Mercurial planet hypothesized by Jacques Babinet in 1846).

\section{II}

The argument from Kripke's rejection of descriptivism about proper names to his contention that "one cannot say of any possible person that he would have been Sherlock Holmes, had he existed" is easy. According to the Kripkean picture no description (not itself embedding the name) is semantically associated with a name. A name is introduced in a baptism in which its reference is fixed - either by a description or ostensively, the latter of which Kripke is willing to bring under the head of association with a description. But then as the name is subsequently used and passed on from user to user the original description may fall away. In subsequent uses the name, still used as the name of the original individual, may be associated with no description or wholly erroneous ones - ignorance and error are no bars to reference with proper names on the Kripkean picture. Secondly, proper names are rigid designators, a proper name has the same reference with respect to every possible world and satisfies the intuitive conjunctive test for this being so given by Kripke: a singular term ' $\mathrm{X}$ ' is a rigid designator if and only if ' $\mathrm{X}$ might not have been $\mathrm{X}$ ' and 'something other than $\mathrm{X}$ might have been $\mathrm{X}$ ' are unambiguously false.

Given this picture of the behaviour of names, Kripke's contention about Sherlock Holmes seems undeniable. There is in fact no man who answers to the description of Sherlock Holmes in the stories (the only description we can possibly regard as fixing its reference, though it may, incidentally, not be implied anywhere in the stories that it is uniquely satisfied), so one cannot say of any possible person that he would have been Sherlock Holmes if he had existed, since different people (merely possible or indeed, actual, such as Darwin and Jack the Ripper) might have performed the exploits of Holmes described in the stories. The argument does not explicitly appeal to Kripke's view that proper names are rigid designators, but it is implicit since it appeals to the idea that different people could have satisfied the only relevant description and therefore no one of them could have 
been Sherlock Holmes since, of course, rigid designators have the same reference across all possible worlds. Of course, although Kripke does not explicitly argue in this way, if 'Sherlock Holmes' is a (nondenoting) rigid designator whose reference is fixed by some such description as 'the consulting detective living at 221B Baker Street and ...', 'it might have been that Sherlock Holmes existed' must have the same truth-value as 'Sherlock Holmes might have existed' and 'the detective living at 222B Baker Street etc., might have existed' (reading the last with the description having wide scope). But the last of these cannot be true, since there is in fact no individual denoted and there are no merely possible individuals (as Kripke would insist), so the description is non-denoting.

Similarly, Kripke's thesis about unicorns can easily be justified given his contention that general terms for natural kinds should be assimilated to proper names of individuals and regarded as nondescriptive rigid designators of these kinds, so that 'tiger' (or 'the tiger') is the rigid designator of an actual species and 'unicorn' (or 'the unicorn') is the rigid designator of a mythical species. There are several distinct hypothetical species (some mammalian, some reptilean) which would have had the external appearance of unicorns in the myth. No one of them can therefore be such that we can correctly say of it that it 'would have been the species of unicorns' if it had existed and been so describable.

All this seems to follow so simply from Kripke's contentions about names and natural kind terms that it is tempting to think that this is the way Kripke's contentions in the Addenda must be argued for, and, therefore, that their plausibility provides further support for his anti-descriptivist picture (in addition to the support provided in the body of Naming and Necessity). Nevertheless, I shall argue, this is not so. Convincing arguments for Kripke's contentions - in fact, some given by Kripke himself - can be given which do not require rejection of descriptivism.

To see clearly what is going, on, however, we need to distinguish two hypotheses (i) that 'Sherlock Holmes' and 'unicorn' are fictional names (of an individual and a kind) and (ii) that they are empty names introduced in error. This is a distinction Kripke notes. (2013: 30-1) The difference is that according to the first hypothesis 'Sherlock Holmes' was never intended, when it was introduced, to name any indi- 
vidual, whereas, according to the second (of course, false) hypothesis it was, but a mistake was made (as actually happened with 'Vulcan'). Mutatis mutandis for 'unicorn'. On either hypothesis Kripke's theses about the unspecifiability of situations which it would be correct to describe as ones in which Sherlock Holmes/unicorns existed can be defended without presupposing anti-descriptivism. But the two defences must proceed somewhat differently.

\section{III}

First let us consider the hypothesis that 'Sherlock Holmes' and 'unicorn' are fictional names. What does this mean? According to many people and argued for wholly convincingly by Kripke in the John Locke Lectures, it means that they are not names at all (in their primary useI will come back to this qualification). They are no more names than a stage murder is a murder. Hence, they are no more non-designating names than they are designating names. They have no semantic value. In the case of 'Sherlock Holmes' what actually happened is that Conan Doyle dipped his pen in ink one morning and began to write a story. That is, he proceeded to pretend that he was a doctor called ' $\mathrm{Dr}$ Watson' with a friend called 'Sherlock Holmes' about whose exploits he was giving an account. He was no more actually writing down a name (non-empty or empty) than the actor on the stage pretending to murder a vicar is actually murdering a vicar. The actor is doing something. He might, for example, be hitting a fellow actor over the head with a piece of foam shaped like a hammer, but he is not murdering a vicar. Similarly, Conan Doyle was doing something. He was making marks on paper, with certain shapes familiar to readers of English, but he was not writing a name (something semantically evaluable as designating or not), or writing sentences containing a name semantically evaluable as true or false. As Kripke puts it:

[N]ames which occur in fictional discourse are, so to speak, "pretended names", part of the pretence of the fiction. The propositions in which they occur are pretended propositions rather than real propositions; or rather, as we might put it, the sentences pretend to express a proposition rather than really doing so. (2013:29)

Of course, what Kripke says here is not quite what he means, since he is here not considering genuine names, like 'London', which are 
also used in fiction (he considers them elsewhere 2013: 24). But the important thing to note is the careful qualification. Names which occur in fictional discourse are 'so to speak' pretended names; in truth they are no more names than stage murders (most of them!) are not murders. The propositions in which they occur are pretended propositions, not real ones, 'or rather, the sentences pretend to express a proposition rather than really doing so'. When Conan Doyle wrote the Holmes stories he was not therefore telling the truth, but nor was he telling lies (contrary to Russell's claim that fiction is a pack of lies). He was not making any assertions or performing any sort of illocutionary act at all. He was, as said, merely pretending to be a doctor making assertions about a friend of his called 'Sherlock Holmes' (note that we cannot say 'he was pretending to be a doctor making assertions about his (i.e., the doctor's) friend, Sherlock Holmes'). He was therefore producing nonsensical marks juxtaposed, of course, with real words (as in 'Holmes lived in London'), just as the actor on stage pretending to murder a vicar is performing certain actions directed towards real things and people (the props and other actors), though he is not performing the action of murdering directed towards someone who is a vicar.

The same is true, on Kripke's account of the first use of 'unicorn'. Something analogous to Conan Doyle's writing the first Sherlock Holmes story occurred and the fiction of unicorns was instituted. So 'unicorn' is not a name of a non-existent natural kind; it is not a name at all. Sentences in the story are not genuine truth-evaluable sentences, and so on.

Illuminatingly, in Reference and Existence (2013: 51) Kripke discusses Lewis Carroll's nonsense poem 'Jabberwocky' and, in particular, the nonsense term, 'bandersnatch' ('bandersnatch' as nonsense should be contrasted with the contradictory term 'round square'; we know this is contradictory precisely because we know its meaning, so it is not nonsense). To say that there are no counterfactual circumstances which it would be correct to describe as ones in which 'Sherlock Holmes existed' or 'unicorns existed', he says, is on a par with saying that there are no counterfactual circumstances it would be correct to describe as ones in which 'bandersnatches existed'. Lewis Carroll's term is merely more obviously lacking in sense than 'Sherlock Holmes' or 'unicorn' because “we are not told any surface 
characteristics, other than that a bandersnatsch is frumious; and apparently a frumious animal is a very dangerous one, or anyway one that should be shunned" (2013: 51). An important difference which makes it more evident that 'bandersnatch' is a nonsense term is that it is not associated with any superficial characteristics and, in fact, a creature's surface characteristics are, in fact, a pretty good guide to what species it is. Hence we are less inclined to regard 'unicorn and 'Sherlock Holmes' as nonsense terms. But really, they are, "the situation is not really so different":

The term 'bandersnatch' is just a pretended name of a species; it doesn't really designate a species, and once one knows that this is the case one cannot say under what circumstances there would have been bandersnatches. ... I think that the case of 'unicorn' is no different [given] that the term 'unicorn' is merely pretense, no hypothetical species is named. ... And the status of the predicate 'is a unicorn' should be precisely analogous to that of the hypothetical name 'Sherlock Holmes'. (2013: 52-3)

Earlier Kripke (2013: 47, fn. 15) sums up the point: "I should not be taken as saying that it is impossible that there could have been ... unicorns. ... Rather, the counterfactual possibility is ill-defined, given that there are no unicorns."

All of this is so evidently correct that the reader may be wondering why I am labouring the point. But the important thing to notice, for present purposes, is that one does not have to reject descriptivism or accept Kripke's historical chain picture to acknowledge it. The account is an account of storytelling as pretence and the consequences of that. It can be accepted on its merits irrespective of one's view of the right thing to say about genuine names and natural kind terms used outside any pretence. Kripke emphasises this. He notes that some descriptivists have thought that it was an advantage of their position that they could account for fictional proper names. For example, a merit of descriptivism, it has been claimed, is that it can account for the meaningfulness of 'Odysseus was set ashore at Ithaca while sound asleep' (Frege) or even the truth-evaluability of sentences containing the name 'Apollo' or 'Hamlet' (Russell). ${ }^{2}$ But Kripke rejects this:

\footnotetext{
${ }^{2}$ Of course, the standard arguments against descriptivism, stated in Naming and Necessity (1980: 27-9) and set out, for example, in the first chapter of the introductory text by Ahmed (2006) do not appeal to the phenomenon of fiction.
} 
The existence of fiction is a powerful case for absolutely nothing, it cannot settle the question between the Russellian theory and the Millian theory. Nor can it settle the question between Mill's theory and any other. $(2013: 23)$

This is because,

when one writes a work of fiction it is part of the pretence of the fiction that the criteria for naming, whatever they are, are satisfied.... Far from it being the case that a theory of the reference of names ought to make special provision for the possibility of such works of fiction, it can forget about this case, and then simply remark that, in a work of fiction ... it is part of the pretence .... that these criteria are satisfied.... So I will call this 'the Pretense Principle' ... it would apply to any theory of naming whatsoever. (2013: 23-4)

So, to labour the point yet again, someone who endorses even the most unsophisticated form of the description theory of names, has no truck with the notion of a rigid designator and simply says that names and natural kind terms are merely abbreviations for definite descriptions, fully synonymous and interchangeable with them in all contexts, can perfectly well agree that circumstances it would be correct to describe as ones in which Sherlock Holmes existed are ill-defined because 'Sherlock Holmes' is not a name; it is merely a part of the pretence that it is, and hence part of the pretence that the criteria for its being so (i.e., its being, he says, synonymous with a description) are satisfied. The same holds, mutatis mutandis, of 'unicorn', and in this way the two cases are exactly the same as that of 'bandersnatch', about which it is merely a pretence of Carroll's that it satisfies the criteria for being a name of a kind of unpleasant animal.

So a theorist who thinks that 'Sherlock Holmes' and 'unicorn' are fictional terms can accept Kripke's Addenda contentions about them without being under any pressure to reject descriptivism.

Of course, there are more things to be said about Kripke's account of fiction making as pretence. There are several bones of contention. And someone might think that in order to resolve these one must reject the descriptivist account of genuine names, or at least that a descriptivist will be hard put to resolve these whilst accepting the Kripkean account of fiction-making as pretence. In this way, it might be said, the Kripkean is, after all, in a better position to accommodate Kripke's Addenda contentions about 'Sherlock Holmes' and 'unicorn' by appeal to the fictionality of these terms than a descrip- 
tivist is. I do not think this is so (nor do I think that Kripke himself would wish to endorse this line of thought). But I shall briefly discuss the bones of contention with this in mind.

The first is this. It is not only the case that there are no circumstances which it would be correct to describe as ones in which Sherlock Holmes would have existed, it is also undeniably correct to say 'Sherlock Holmes does not exist and never did'. Similarly, 'unicorns do not exist and never have', and 'bandersnatches do not exist and never have'. But how can this be? This is the problem of negative existentials. It confronts anyone who accepts Kripke's account of fictionmaking as pretence because according to this these 'sentences', on the use the account explains (as components of works of fiction), are neither true nor false but nonsense. Yet plainly, as we standardly use them, they are not.

As Kripke explains, one can easily imagine finding out that things are such that it is correct to say 'bandersnatches exist/did exist'. We could find out that Lewis Carroll's intentions were not what we thought. He was not engaged in storytelling. He was writing, in the form of a poem, a straightforward report of the local fauna in his boyhood neighbourhood. In fact, we might uncover a letter in which he responds to an enquirer by saying that he is quite surprised that people think he is talking about imaginary animals. Actually, he himself used to encounter bandersnatches occasionally when he was a young boy, though he was warned by his parents to avoid them because they were frumious, and indeed these words seem to have dropped out of common use.

Of course, we know that is not the way things are. Carroll was just writing fiction, and we can report this fact by saying that bandersnatches do not exist and never did.

But how, then, is the use of the term in this context to be explained? Kripke struggles manfully with this perplexity and arrives at a complicated story which has satisfied no one and about which he will say only that it is better than anything else he can think of. One worry is that it is in conflict with his own account of naming and requires some sort of notion of indirect reference more at home in a Fregean account (see Salmon 2011: 64). I only want to note now that the problem of these negative existentials does not in any obvious way point to a problem for descriptivists which is not equally a problem for 
Kripkeans, nor does it give any reason to think that descriptivists cannot endorse Kripke's account of storytelling as pretence. Of course, descriptivists have, to the contrary, argued that the intelligibility of negative existentials is a point in favour of their account. But Kripke convincingly shows that this is not so. Whatever descriptive material, 'blahblahblah', pertaining to bandersnatches, we can extract from Carroll's poem, when we say 'bandersnatches do not exist' we do not mean 'there is nothing satisfying the description: blahblahblah', any more than when we say 'unicorns do not exist' we mean 'there is nothing answering to the description ...', where this is one that can be extracted from the unicorn myth, or when we say 'Sherlock Holmes does not exist' we mean 'there is nothing answering to the description ...', where this is one that can be extracted from the Conan Doyle stories. As Kripke says, even if there were, unknown to Doyle, someone actually satisfying such a description it would not be correct to describe the discovery of such a person as the discovery that Sherlock Holmes existed. Whatever the resolution of the problem of negative existentials is, then, there is no reason to think that it must either favour or, the crucial point for our purposes, be inimical to descriptivism. ${ }^{3}$

The second well-known bone of contention about fictional names is their use as names of fictional characters, as in e.g., 'Sherlock Holmes was inspired by one of Doyle's university teachers'. Again, whatever the correct thing to say about this is, this use is no argument against descriptivism or the availability to descriptivists of the Kripkean pretense account of storytelling.

I earlier described the use of 'Holmes' by Conan Doyle as its 'primary use'. But in fact, on the Kripkean story it is not, since it is not a use at all, but a pretence of one. But there does seem to be a genuine use of the name as a name of a fictional character in sentences of the type just mentioned, a use of it as a name of a genuinely existent entity, on a par, as a human creation, with the story, 'A Study in Scarlet', or the United States of America (see Kripke 2011: 63). Kripke recog-

${ }^{3}$ Sophisticated Lewisean descriptivists may suggest that when one says 'Sherlock Holmes does not exist' one means 'there is no such person as the person I have heard of under the name "Holmes", or maybe 'there is no such thing as the causal source of this token: Holmes' (Lewis 1997). But there are objections to this (see Salmon 2011). 
nises this. Similarly, there does seem to be a genuine use of 'unicorn' and 'bandersnatch' as names of fictional kinds, which are not kinds, like the tiger or water, no more than the character Sherlock Holmes is a man, but are nonetheless genuinely existent human creations.

If so, descriptivists need not demur. As genuine names of genuine entities, on their view they will be associated appropriately with descriptions. But saying this does not require them to depart from the Kripkean position that in the original fictions these terms are meaningless 'pretended names', nor therefore is there any difficulty for them in accepting Kripke's Addenda contentions about 'Sherlock Holmes' and 'unicorn' understood as fictional names.

The third bone of contention about fictional names is their apparent use within critical discourse, sometimes, not always, within prefixed assertions like 'In the stories, Holmes was a cocaine addict' or 'In the poem, bandersnatches are fast-moving', which are apparently assessable as true or false. Again, these are problematic for Kripke since what follows the prefix can apparently express no proposition, since the nonsense names are not merely mentioned but used. Kripke refers to these prefixes as 'quasi-intensional' but it is hard to see how they can be (Salmon 2011: 65). Once again, though, whatever one says about how to deal with this problem there seems to be no reason to think that it is any more of a problem for descriptivists than for Kripkeans. Descriptivists might be tempted to think that they are better placed to deal with it than Kripkeans. This seems unlikely, in the light of the arguments given by Kripke, but whether or not this is so, there certainly seems to be no reason to regard this problem as a reason for rejecting descriptivism or thinking that descriptivists cannot follow Kripke in regarding fictional names as merely pretended names. ${ }^{4}$

${ }^{4}$ A possible solution to the problem is to suggest that when the critic says, 'Sherlock Holmes uses cocaine' (something that can verified by reading the stories) he is retelling (part of) the story. That is, he is himself pretending to be a narrator of the activities of someone called 'Sherlock Holmes'. This then, is to be compared with my retelling of the bedtime story of the Three Little Pigs to my child, or perhaps with an actor, or different actors, acting out the same part on repeated occasions. So what he says is neither true nor false, just as Conan Doyle is not writing anything true or false. But about the critic we can ask a question we cannot ask about Doyle: is he in fact retelling Doyle's story or telling or retelling another 
In sum, then, I have argued in this section that contrary to the impression one gets from Naming and Necessity even if Kripke is wrong to reject descriptivism his contentions in the Addenda about 'Sherlock Holmes' and 'unicorns' are still plainly correct if these are fictional names and his account of storytelling as pretence is accepted (as it plainly should be).

But are 'Sherlock Holmes' and 'unicorn' fictional names? 'Sherlock Holmes' certainly is, but I assume it is contentious whether 'unicorn' is. Moreover, even if 'Sherlock Holmes' is a fictional name there are, it seems, non-fictional empty names like 'Vulcan'. But it seems that given that that name is in fact empty, the conclusion that there are no possible circumstances which it would be correct to describe as ones in which Vulcan existed is straightforwardly derivable from Kripke's historical chain picture of reference. This seems to be the correct conclusion, but how can a descriptivist accommodate it?

So, despite the discussion of fiction just completed, the question whether the correctness of Kripke's Addenda contentions, appropriately generalized, is an argument against the description theory arises again. My view, explained in this section, is that though the question arises, it has a negative answer.

First, I need to be clear about the distinction between a fictional name like 'Sherlock Holmes' and an empty name like 'Vulcan'. I take it, following Kripke (2013: 31) that the distinction is that 'Sherlock Holmes' was introduced as part of a pretence by Conan Doyle who knew that was what he was doing, whereas the introduction of 'Vulcan' was a mistake, a product of false belief. Thus, there was no attempt to introduce 'Sherlock Holmes' as a name by Conan Doyle. It was part of the pretence that it had already been introduced,

one? This is the question whether his retelling is faithful to the original (which is what we have in mind in speaking of truth here). As for the prefixed assertion 'In the story Holmes takes cocaine', perhaps the prefix can be read as a scene-setting announcement: I am about to retell (part of) the story. Wait for it:' This is suggested by Predelli (2020: 84ff.). The only point I want to note is that this account (on which there is no use of a name by the critic any more than there is by Conan Doyle) is as much available to the descriptivist as the Kripkean. 
presumably by Sherlock's parents, whereas 'Vulcan' was introduced (by Babinet) but the introduction failed. What actually goes on in the introduction of a name will be disputed by descriptivists and Kripkeans. But they will agree that for any genuine name there has to be an introduction, successful or not.

So consider the following case, which all will agree constitutes the introduction of a name. I fix the reference of the name 'Tom Jones' by stipulating that it is to name the man presently living in the old house over the river there who is always so rude and unsociable. Both descriptivists and Kripkeans will agree that if the description denotes my naming ceremony will have succeeded. Kripkeans will say that I have introduced a rigid designator the reference of which is merely fixed by the description and no association with the description or any description is needed for subsequent successful use of the name. Descriptivists will not agree. They will insist that some identifying knowledge of the bearer is required for successful reference, though they need not say that the name is synonymous (after its introduction) with the original introducing description, and they will not say that the name is a Kripkean rigid designator, though they may say (and arguably have to say) that in modal contexts its use is by conventionally typically that of a wide-scope description (Dummett 1973: 127ff., 1981; Lewis 1984: 223). But despite their disagreements they will agree that if the reference-fixing description denotes, the name will have been successfully introduced as the name of its denotation, and if the description does not denote (e.g., because there are in fact two men in the house) the introduction has misfired and 'Tom Jones' in this use is an empty name.

Now in this case the Kripkean will say that since 'Tom Jones' is a rigid designator of nothing 'Tom Jones could have existed' is false and so there are no circumstances it would be correct to describe as ones in which Tom Jones would have existed. There might be other circumstances in which a single man was in the house, in different circumstances different men, and these need not be merely possible men, but could be (different) actual men. But there is no circumstance of which it would be correct to say, 'If that circumstance had obtained Tom Jones would have existed'. For if so, which one?

So even though 'Tom Jones' is a genuine name, not a fictional name, it is still the case that there is no possible world properly de- 
scribable as one in which Tom Jones would have existed. The difference made by the name being empty rather than merely fictional is just that 'Tom Jones could have existed' is false rather than, like 'Sherlock Holmes could have existed', meaningless.

Now, however, the descriptivist can just say the same about the empty case, as long as he does not regard 'Tom Jones' as synonymous, interchangeable in all contexts, with its reference-fixing description and so a flexible designator. Given that there are two men living in the house, the statement 'The man living in the house might have existed' is ambiguous between a true statement with the description given narrow scope, and a false one with the description given wide scope. Hence if the name behaves by convention as a wide-scope description in such modal contexts (which appears to be what descriptivists have to say to account for the observed linguistic phenomena) 'Tom Jones could have existed' is false. So descriptivists, like the Kripkean, can accommodate Kripke's Addenda observations about 'Sherlock Holmes' even if it is not a fictional name, but an empty one.

What about the unicorns? It is, of course, unclear whether 'unicorn' is a fictional name of a kind, like 'bandersnatch, 'tove', 'alicorn' ${ }^{\prime 5}$ and probably 'dragon' - maybe there is no right answer. But even if 'unicorn' is an empty name rather than a fictional name, given the Kripkean assimilation of natural kind terms to proper names of individuals and the reasoning by which the Kripkean can establish the necessary non-existence of the bearers of empty names, it is unproblematic that Kripkeans can affirm that there are no circumstances it would be correct to describe as ones in which unicorns existed. The remaining question then is whether a descriptivist can endorse this conclusion. He can affirm the corresponding thesis containing empty names of individuals because he can endorse widescope descriptivism for them (Dummett 1973, 1981, Lewis 1984). Comparably, he can endorse widescope descriptivism for natural kind terms, like 'tiger', and maintain that they differ in their behaviour in modal contexts from descriptions like "large carnivorous, quadrupedal cat-like animal, tawny-yellow in colour with blackish transvers stripes and a

\footnotetext{
${ }^{5}$ From the children's My Little Pony television series. Princesses Celestia and Luna are alicorns, unicorns with wings (though it is disputed on Wikipedia whether they have been so from birth).
} 
light belly' (Kripke 2013: 44, quoting the Oxford English Dictionary). If he can do this he can explain why, assuming 'unicorn' is an empty natural kind term, 'unicorns could not have existed, like 'Tom could have existed', is false.

But the value of the explanation thus available to the widescope descriptivist may be challenged, given that it depends upon an appeal to a general convention which makes false a wide range of modal statements. ${ }^{6}$ It is important then to note that the widescopist convention need not be regarded as ad hoc. Typically, such descriptivists hold that different descriptions, some deferential, are associated with a name by different speakers and at different times. Given such variation in descriptive association a convention whereby names should be given wide scope in modal contexts has an easily comprehensible rationale, stated briefly by Lewis (1984: 243, with footnote acknowledgement to Noonan 1979):

There may or may not be rigidification. If there is that will avoid confusion between people who have attached the same name to the same referent by different descriptions. For nothing will be true as one person means it, but false as the other means it, not even when the name appears in modal contexts. ${ }^{7}$

${ }^{6}$ But note here exactly what the widescopist descriptivist's convention is: it is that names have wider scope than modal operators; it is not that they have wider scope than any operators, including, for example, negation. Thus, according to the widescopist view the name has wider scope than the modality in 'Vulcan could have existed' (though note the caution in footnote 7). But it is left open whether the name has wider scope than the negation in 'Vulcan necessarily doesn't exist' (compare the non-modal negative existential 'Vulcan doesn't exist' — of course, the Kripkean has difficulties with both of these if he wants to say that they are true since it is not true of anything that it is a (necessary) non-existent). In fact, it is consistent for him to hold that other conventions governing the scope interaction of names with negation in existential statements require the negation to have wider scope than the name in these negative existentials. He can alternatively consistently say that 'Vulcan necessarily doesn't exist' must be read with the name having widest scope, the modal operator intermediate scope and the negation narrowest scope and so the statement must be read (like 'the present King of France/the round square necessarily doesn't exist') as self-contradictory.

${ }^{7}$ Of course, what one does not do only because one is following a convention is something one can do. And when the rationale for the convention does not apply one may. Thus, Dummett (1973: 111ff.) considers the name 'St Anne', which is such, he assumes, that all users associate it with the description 'The mother of 
But it may be objected that the widescopist strategy cannot, in fact, adequately explain Kripke's explananda on the assumption that the relevant names are empty and not fictional. For (here I quote an anonymous referee):

It can help descriptivists only as far as modal sentences are concerned. ... It can allow them to say that the sentence 'Vulcan could have existed' is false. But consider the non-modal sentence 'Vulcan exists'. According to the descriptivist it expresses the same proposition as the existential sentence containing the definite description allegedly synonymous with 'Vulcan'. But if as assumed the description is only contingently empty, that proposition is only contingently false. Then there are possible circumstances relative to which the proposition expressed by 'Vulcan exists' is true. Now aren't these circumstances in which Vulcan exists, or, to use Kripke's phrase, circumstances properly describable as ones in which Vulcan would have existed?

The answer is 'No'. The referee's question in effect challenges the widescopist to deny that 'There are possible circumstances in which Vulcan exists' is true. But the sentence 'there are possible circumstances in which Vulcan exists' is not understood unless it is understood as strictly equivalent to 'Vulcan could have existed' (Kripke 1980: 18 , fn. 16). ${ }^{8}$ The latter is a modal sentence. So to be successful the

the Virgin Mary', know nothing more and know that all other users are in the same condition (in his 1991: 48 he presents the same argument against Kripke substituting St Joachim' (the father of the Blessed Virgin) for 'St Anne' to make this point more obvious). In this case, he argues, the reading with the name having narrow scope comes into view, so 'St Anne might never have been a parent' will be heard as ambiguous. He notes that Kripke can say the same but will locate the ambiguity in the type of modality in question, epistemic or metaphysical, whereas he thinks, appeal to scope is the more conservative explanation. Kripke himself gives 'Jack the Ripper' (1980: 79) as a similar example. 'Vulcan' may, in fact, have the same status. Donnellan (1977) argues that in the case of such unusual names as 'St Anne or 'Jack the Ripper', or Kripke's example 'Neptune', as first used by Leverrier, which are pegged to an introducing description during a particular time period, the name may in that time period be indeterminate between a rigid designator and a flexible designator. This is consistent with Dummett's position.

${ }^{8}$ That is the short answer. The referee is, of course, expounding the anti-widescopist response of Kripke's Preface in the 1980 edition of Naming and Necessity, which is replied to by, amongst others Dummett $(1981,1991)$. A key part of the reply is that (even given that 'Vulcan' is associated at all times only with the description 'the intra-Mercurial planet') 'Vulcan exists' is not synonymous with 'the intraMercurial planet exists'. It is part of our understanding of the former sentence, 
widescopist's strategy only needs to help as far as modal sentences are concerned. So I conclude that a sophisticated widescopist account of names of individuals and kinds can accommodate the intuition that, assuming that 'Vulcan' and 'unicorn' are empty names, there are no possible circumstances properly describable as ones in which Vulcan would have existed and no possible circumstances properly describable as ones in which unicorns would have existed.

The point is perhaps harder to see in the latter case because whether 'unicorn' is in fact a merely empty term or a fictitious name is unclear. So I will finish by sketching a hypothetical case of something which is clearly an empty natural kind term. In Material Beings (1990: 104) van Inwagen imagines a community, the inhabitants of Pluralia, who are in contact (from a distance) with what appears to be a kind of large, black, very timid, tiger-like animal. They introduce the term 'bliger'. Later they discover that there are no bligers. What appears to be a bliger is really six animals. Its 'legs' are four monkey-like creature, its 'trunk' a sort of sloth, and its 'head' a species of owl. The illusion is amazing.

There are no bligers, nor is there any circumstance of which

unlike the latter, according to the descriptivist, that one recognises that it contains a name, hence is subject to the widescopist convention. But what one understands when one understands a sentence is its meaning. Hence the two sentences differ in meaning and in one sense of 'proposition' express different propositions. In another sense they express the same proposition: what one asserts when one utters either assertively is the same. Dummett thus distinguishes between ingredient sense (wherein the sentences differ) and assertoric content (wherein they are identical) (Dummett 1981: 572, 1991: 48). Evans (1978) accepts Dummett's distinction, using 'proposition' for 'ingredient sense' and identifying the proposition expressed by a sentence with a function from worlds to truth-values (see Rabern 2017 for a survey of related literature). Thus, in Evans's scheme the proposition expressed by 'Vulcan exists' is a function whose value for any argument is the truthvalue $\mathrm{F}$, whereas the proposition expressed by 'the intra-Mercurial planet exists' is a function whose value for a world $\mathrm{w}$ is $\mathrm{T}$ iff it is true relative to $\mathrm{w}$ that there is a unique intra-Mercurial planet. So the referee's statement 'there are possible circumstances relative to which the proposition expressed by 'Vulcan exists' is true' is true only if 'proposition' is read as 'assertoric content'. But the inference to 'there are circumstances in which Vulcan exists' is valid only if 'proposition' is read as 'ingredient sense'. What is undeniable is that 'there are possible circumstances in which Vulcan exists' must be understood as having the same truth-value as 'Vulcan could have existed'. 
it would be correct to say 'if that circumstance had obtained there would have been bligers' (though, of course, if the circumstance had been as the Pluralians originally supposed they would have been correct in asserting 'There are bligers'). 'Bliger' as it is supposed to be used in this story is not a fictional name; it is an empty name, like 'Tom Jones' if in fact there are two men living in the house by the river. However, the Kripkean view that there is no possible circumstance correctly describable as one in which 'there would have been bligers' is correct but, I have argued, can be accommodated by the (sophisticated) descriptivist as well as the Kripkean.

\section{V}

I conclude that even if Kripke is wrong to reject descriptivism in the body of Naming and Necessity, he is right in the Addenda in his contention that no circumstance is properly describable as ones in which Sherlock Holmes or unicorns existed and that this is so whether these are fictional names or merely empty ones, though the reasons differ in the two cases, and only a sophisticated widescopist descriptivist (like Dummett or Lewis) can agree with Kripke if, in fact, these names are merely empty.

Harold Noonan University of Nottingham Department of Philosophy University Park Nottingham, NG7 2RD

Harold.Noonan@nottingham.ac.uk

\section{References}

Ahmed, Arif. 2006. Kripke. New York: Continuum.

Biggs, Stephen and Geirsonn, Heimir (eds.) 2021. The Routledge Handbook of Linguistic Reference. New York: Routledge.

Chalmers, David J. 2002. On sense and intension. Philosophical Perspectives 16: 13582.

Donnellan, Keith. 1977. The contingent a priori and rigid designators. Midwest Studies in Philosophy 2: 12-27.

Dummett, Michael. 1973. Frege: Philosophy of Language. London: Duckworth, $2^{\text {nd }}$. ed., 1981.

Dummett, Michael. 1981. The Interpretation of Frege's Philosophy London: Duckworth. 
Dummett, Michael. 1991. The Logical Basis of Metaphysics, Harvard: Harvard University Press.

Evans, Gareth. 1979. Reference and contingency. The Monist 62: 161-89.

Jackson, Frank. 1998. Reference and description revisited. Philosophical Perspectives 12: 201-18.

Jackson, Frank. 2010. Language, Names and Information. Oxford: Wiley-Blackwell.

Kripke, Saul. 1980. Naming and Necessity. Oxford: Basil Blackwell.

Kripke, Saul. 2011. Philosophical Troubles. Oxford: Oxford University Press.

Kripke, Saul. 2013. Reference and Existence:The John Locke Lectures. Oxford: Oxford University Press.

Lewis, David. 1984. Putnam's paradox. Australasian Journal of Philosophy 62: 22136 -

Lewis, David. 1997. Naming the colours. Australasian Journal of Philosophy 75: 32542 .

Noonan, Harold W. 1979. Rigid designation. Analysis 39: 174-82.

Predelli, Stefano. 2020. Fictional Discourse: A Radical Fictionalist Semantics. Oxford: Oxford University Press.

Rabern, Brian. 2017. A bridge from semantic value to content. Philosophical Topics 45(2): 181-207.

Salmon, Nathan. 2011. Fiction, myth and reality. In A. Berger (ed.) Saul Kripke (pp. 49-77). Cambridge: Cambridge University Press.

Soames, Scott. 2005. Reference and Description: The Case Against Two-Dimensionalism. Princeton: Princeton University Press.

Van Inwagen, Peter. 1990. Material Beings Ithaca: Cornell University Press. 